\title{
Protecting the Public's Health Following the Virginia Tech Tragedy: Issues of Law and Policy
}

\author{
James G. Hodge, JD, LLM
}

\section{ABSTRACT}

Assessing legal responsibility in the aftermath of the April 2007 tragedy at Virginia Polytechnic Institute and State University (Virginia Tech) is inevitable. Beyond assigning blame, law- and policymakers should examine ways to protect the public from future incidences of gun violence on campuses and other settings. Although no combination of legal responses may fully deter individuals who are intent on causing significant harm, select legal reforms have the potential to prevent future acts of gun violence. These reforms include considering more restrictive gun laws nationally, reporting individuals with known mental impairments that may endanger themselves or others to federal or state databases, and refining laws that limit institutions from acting in advance to address prospectively dangerous people. Each of these reforms has the potential to reduce acts of gun violence to improve the public's health, but also implicates individual rights and interests. (Disaster Med Public Health Preparedness. 2007; (Suppl 1):S43-S46)

Key Words: public health, gun violence, mental health, privacy, policy, law

$\mathrm{T}$ ragedies can defy society's beliefs about what is possible in a short period of time. Each day on average in the United States, more than 80 people are killed by firearms. ${ }^{1}$ Some may view this as tragic, especially considering that similar death rates by guns in other industrialized countries with substantially more restrictive gun laws are significantly lower. However, when 33 human beings, including the instigator, are killed in a single outbreak of violence at a prominent university, members of the national media and others are quick to label the event a "massacre." And so they should. What occurred at Virginia Polytechnic Institute and State University (Virginia Tech) on April 16, 2007 is catastrophic. No words can fully explain the losses of human life; the physical and emotional impact on families, friends, and others; or the collective anxieties felt across the nation following this occurrence. The tragedy at Virginia Tech was the most lethal school shooting episode in US history.

In the aftermath of the shootings, a host of legal and other questions have swirled about: How did SeungHui Cho, a 23-year-old student at Virginia Tech, obtain the semiautomatic handguns he used to commit these acts? What was his mental status during his time as a student at Virginia Tech, before he obtained the guns, and before he actually used them? Did campus security act appropriately to protect the campus population? 2 Were campus warning systems effective in real time? At the core of these issues is a central public health inquiry: How could this tragedy have been prevented?

From a legal perspective, the simple answer is that perhaps it could not have been prevented. ${ }^{3}$ No collection of legal responses to such tragedy can guarantee that similar occurrences will not happen again. ${ }^{2}$ However, a series of legal and policy proposals emanating from the Virginia Tech massacre could greatly limit the possibility of these events in the future, as well as curtail daily gun-related violence in the United States. They include proposed changes to existing laws to prevent injuries and deaths through new restrictions on access to guns, require more extensive reporting of individuals with mental incapacities to authorities, and enhance campus security. As discussed below, each of these proposals is motivated by the need to protect the public's health, but all of them may involve diminutions in individual interests.

\section{RESTRICTIONS ON ACCESS TO GUNS}

Seung-Hui Cho purchased the semiautomatic handguns he used during his rampage from a pawnshop and a gun store in the Commonwealth of Virginia. Virginia's firearms access laws are considered among the most permissive in the nation. Consistent with the Brady Handgun Violence Prevention Act of $1993^{4}$ and Virginia state law, the store owner conducted a hasty background check using the federal National Instant Check System (NICS) to determine whether Cho was qualified to purchase guns. In 
2005 a Virginia state magistrate had deemed Cho a potential danger to himself because of his mental status. ${ }^{5}$ This information likely would have legally disqualified him from purchasing handguns, but it was not reported to federal or state authorities. Correspondingly, Cho was allowed to purchase guns after the brief background check. ${ }^{5}$

Unfortunately, similar approvals may be replicated across many states. The federal Firearm Owners' Protection Act of 1986, ${ }^{6}$ which amended the federal Gun Control Act of $1968,{ }^{7}$ enunciates a series of disqualifying criteria about who may purchase a gun in the United States. They include persons who have been adjudicated as "mental defectives" or who have been committed to a mental institution. ${ }^{8}$ Many states' laws feature similar provisions. Collectively, however, these laws do not guarantee that individuals like Cho will be reported to federal background databases for reasons examined below.

More important, neither federal nor Virginia state law offers much discretion to gun shop owners to reject purchasers on other grounds. ${ }^{9}$ In Virginia, handguns are easily purchased, almost on demand. If Cho had not gotten his handguns at a licensed gun shop, then he could have simply bought 1 or more guns at local gun shows where private sellers routinely sell and swap firearms, with no legal requirement to conduct background checks. ${ }^{10}$ Although many states' gun access laws are similar to those in Virginia, other states feature more restrictive policies. Discretionary licensing laws in California, Hawaii, Massachusetts, New Jersey, and New York, for example, limit handgun ownership by requiring purchasers to undergo extensive background checks to acquire a license before purchasing guns. ${ }^{5}$ These licensing schemes have survived constitutional scrutiny in part because of their overriding purpose to protect the public's health. ${ }^{9}$

The inconsistency of gun access laws nationally has led to another problem in states with more restrictive access laws. Individuals may simply purchase their guns in permissive access states to use elsewhere. New York City mayor Michael Bloomberg is part of a coalition of more than 200 US mayors that has brought suit against authorities in Virginia and other states to address the sale of guns in these jurisdictions that are subsequently used in New York City. ${ }^{1}$ Local authorities have been able to support their claims of interstate gun trafficking by tracing guns across jurisdictions through gun registration databases.

Recently introduced in the US Senate, the Anti-Gun Trafficking Penalties Enhancement Act of 2007 may further enhance the ability of authorities to track stolen firearms and guns used in crimes. ${ }^{11}$ If passed, state and local government agents would have greater access to information contained in the federal Bureau of Alcohol, Tobacco, Firearms and Explosives' Firearms Trace Systems database. In contrast, the Tiarht Amendment, named after its Congressional sponsor, Kansas Republican Representative Todd Tiarht, ${ }^{12}$ seeks to limit access to trace data to analyze the flow of guns used in crimes across the nation. If reapproved by Congress (as it has for years now), this law could hamper the ability of law enforcement officials to combat illegal gun trafficking ${ }^{13}$ in the interests of protecting community health and safety.

\section{DISCLOSING MENTAL HEALTH RECORDS}

If federal and state laws generally prohibit people with disabling mental conditions, like Cho, from purchasing guns, then why did his mental status not show up on his background check? In addition, why are people with similar mental states not routinely reported to state or federal authorities for inclusion in the NICS? Answers to these questions are mired in competing claims, divergent interests, money, and politics.

NICS was established through the Brady Act to improve national surveillance of people who are prohibited from purchasing a firearm via federal law. NICS is a computerized database that provides essential data to licensed firearm dealers (and others) from varied sources ${ }^{14}$ for instantaneous background checks conducted before the sale or transfer of a firearm. ${ }^{15}$ As conceptualized, the system is a valuable, electronic surveillance tool to limit forbidden gun sales. As operated, however, NICS is more of an empty shell. No state is actually required to submit any data to the system. A federal bill sponsored by New York Democratic Representative Carolyn McCarthy and Senator Charles Schumer, would require states to submit mental health data to the system and provide federal resources to help ensure compliance. ${ }^{16}$

Even among the 22 states that voluntarily choose to submit data despite a lack of existing federal resources, ${ }^{17}$ individual mental health data are not consistently reported for 2 primary reasons:

1. It is not clear what qualifies a person as "mentally defective" under federal or state law. Cho was voluntarily admitted to an outpatient psychiatric center in 2005 based on a judge's recommendation and later released. Because he was not forcibly committed to a mental institution, his mental health records were not shared with state officials, and correspondingly not distributed to NICS. ${ }^{10}$ Following the Virginia Tech tragedy, Virginia governor Timothy M. Kaine signed an executive order requiring anyone who receives court-ordered mental health treatment, whether inpatient or outpatient, to be included in the law as someone who is prohibited from purchasing firearms. ${ }^{10,18}$ Other states have since debated the legitimacy of Virginia's inclusion of mental health outpatients. A policy secretary for Pennsylvania governor Ed Rendell noted that mental diagnoses "are not consistent across settings [or] doctors." 17 Whether someone is "mentally defective" under the federal legal standard is hard to define. There is a lack of consensus as to what types of personal mental health data should be shared with law enforcement officials in background check databases. Virginia's determination that court-ordered mental health treatment per se 
qualifies a person for inclusion in the NICS database is seemingly good policy, but what if someone is simply recommended for mental health interventions? What if he or she voluntarily seeks mental health services? Judgments as to who qualifies for inclusion in NICS will vary, as will the types of people reported. Labeling all individuals who seek mental health treatment as ill-suited for gun ownership implicates issues of fairness and equity. Only a small percentage of such individuals are a danger to themselves or others. Careful consideration of the criteria for inclusion of people with mental illness in NICS is needed.

2. Privacy laws and policies may prohibit the sharing of sensitive, individually identifiable mental health records. Even assuming that agreement exists on the types of people with mental conditions who should be reported, sharing identifiable mental health data may be contrary to privacy laws and policies in some jurisdictions. Mental health advocates and others argue that the privacy of individuals seeking mental health services is paramount. ${ }^{5,19}$ Many state privacy laws, for example, protect the privacy of mental health records at a higher level than other health data. ${ }^{5}$ Mental health data are viewed by many as "supersensitive" because of the intimate nature of information divulged via mental health counseling and the potential for discrimination and stigmatization following unwarranted uses or disclosures of such data. ${ }^{20}$ Some state policymakers opine that their existing mental health privacy laws prohibit the sharing of identifiable data with law enforcement authorities for NICS.

Protecting the privacy of people seeking mental health services is an important societal goal. Lacking privacy expectations, some individuals may feel constrained to discuss their condition with mental health care workers. Others may avoid mental health services altogether. However, individual privacy must consistently be balanced with community needs to access data. The federal Health Insurance Portability and Accountability Act Privacy Rule restricts access to personally identifiable health information (including mental health data), but permits some disclosures without written authorization in the interest of public health, safety, or welfare. ${ }^{21}$ Privacy laws that do not allow the responsible sharing of the mental health data of individuals who pose dangers to themselves or others with confidential systems to limit access to guns should be amended carefully. 22,23

\section{ENSURING A SAFE SCHOOL ENVIRONMENT}

Protecting the public's health sometimes requires restricting the rights or privileges of a selective few for the protection of the community. In the case of Seung-Hui Cho, some question why a student who was adjudicated as needing mental health treatment, who had a history of violent encounters with others on campus, and who expressed strongly violent thoughts in some of his coursework was not summarily dismissed from the campus environment before April 16, 2007. It may have been because federal and state laws arguably do not support such action. The federal Americans with Disabilities Act provides broad protections for people with physical or mental disabilities, or people perceived to have a disability, from unwarranted discrimination in academic settings. Virginia was the first state to enact legislation barring its public colleges and universities from expelling students for attempting to commit suicide or seeking mental health treatment for suicidal thoughts or behaviors. ${ }^{24}$

Underlying these antidiscrimination laws are policies that are intended to protect thousands of students from the rash decisions of universities to excuse them from campus based solely on their mental health status. According to a 2006 survey of 95,000 students on 117 campuses nationally, up to $16 \%$ of students reported considering suicide or suffering from depressive thoughts that limited their capacity to function..$^{23}$ These at-risk students often need mental health care, which is sometimes provided directly by colleges, but they may be reluctant to seek help if they are penalized or excused from campus as a result.

Whether Virginia Tech authorities should have dismissed Cho from campus is a question best left to independent finders of fact to judge. Colleges and universities are conflicted in deciding whether or when to expel at-risk individuals from their communities. ${ }^{23}$ Categorically excluding individuals with mental disorders surely runs afoul of antidiscrimination laws and student privacy provisions under the Family Educational Rights and Privacy Act (FERPA). ${ }^{25}$ FERPA generally prevents disclosure of educational records, which may include health information, without written authorization; however, FERPA allows disclosure without informed consent in connection with a health or safety emergency. ${ }^{26}$ What constitutes an "emergency" pursuant to FERPA is often left to the discretion of education officials. Diagnosis of a student's psychological disorder alone may not constitute a situation that jeopardizes the health or safety of the student or others sufficient to justify disclosure to law enforcement or education authorities. Yet failure to disclose such information can sometimes lead to tragic incidents. The paradox is that either decision may expose the institution to potential liability. Worse yet, even if Virginia Tech had expelled Cho before April 16, 2007, the open access of its buildings and campus may still have allowed this tragedy to occur.

\section{CONCLUSIONS}

Assessing legal responsibility following any tragedy is inevitable. What law- and policymakers need to do is move beyond assigning blame and look to how to re-craft laws to protect the public from future incidences of gun violence. No combination of legal maneuvers may fully protect society from the outrageous acts of an individual who is intent on causing extensive harm. However, select legal improvements can prevent others from falling victim to acts of violence involving firearms. Examining more restrictive gun laws nationally, routine reporting to authorities of individuals with known mental impairments who may endanger themselves or others, and reconsidering laws that bind institutions into 
inaction concerning prospectively dangerous people have the potential to improve the public's health through the reduction of acts of gun violence.

\section{About the Author}

James G. Hodge Jr is with the Johns Hopkins Bloomberg School of Public Health.

Correspondence and reprint requests to James G. Hodge Jr, Johns Hopkins Bloomberg School of Public Health, Hampton House, Room 588, 624 N Broadway, Baltimore, MD 21205-1996 (e-mail: jhodge@jhsph.edu).

Received for publication May 25, 2007; accepted June 19, 2007

\section{Acknowledgment}

The author gratefully acknowledges the research and editing contributions of Dhrubajyoti Bhattacharya, JD, MPH, Johns Hopkins Bloomberg School of Public Health.

ISSN: 1935-7893 @ 2007 by the American Medical Association and Lippincott Williams \& Wilkins.

DOI: 10.1097/DMP.0b013e3181454190

\section{REFERENCES}

1. CDC National Center for Injury Prevention and Control. WISQARS. Based on 2002-2004 data. Centers for Disease Control and Prevention Web site. http://www.cdc.gov/ncipc/wisqars. Accessed June 14, 2007.

2. Kronenberg J. Liability laws put colleges in crunch. Boston Herald. April 22, 2007:26.

3. Silber J. To shield all tragedy an impossible quest. Boston Herald. April 24, 2007:A7

4. Pub L No. 103-159, 107 Stat 1536 (November 30, 1993), codified at 18 USC $\S 921$ and 18 USC $\S 922$.

5. Luo M. Mental health and guns: do background checks do enough? New York Times. April 19, 2007:A1.

6. 18 USC 921 et seq.

7. Pub L No. 90-618, 82 Stat 1213, 44 USC 18.
8. 18 USC $921(\mathrm{~d})(4)$

9. Vernick JS, Mair JS. How the law affects gun policy in the United States: law as intervention or obstacle to prevention. J Law Med Ethics. 2002;30 (4): 692-704.

10. Va. guv bans gun sales to those on risk list. Newsday. May 1, 2007:A25.

11. HR 1895 (110th Congress, 2007-2008).

12. Getting the guns: mayors want access to gun source data. The Record. April 19, 2007:L6.

13. Rauh G. Bloomberg anti-gun campaign to air ads. New York Sun. April 19, 2007:3.

14. National Instant Criminal Background Check System. US Department of Justice. Federal Bureau of Investigation, Criminal Justice Information Services Division Web Site. http://www.fbi.gov/hq/cjisd/nics/nicsindex.htm. Accessed May 24, 2007.

15. 18 USC 922

16. HR 297 (110th Congress, 2007-2008).

17. Urbina I. Virginia ends a loophole in gun laws. New York Times. May 1, 2007:A6.

18. Raffaele M. Pa. unlikely to follow Va. on broad mental health gun restriction. www.phillyburbs.com/pb-dyn/news/103-05052007-1341777. html. May 5, 2007.

19. Graham J. Gun database lacks Mass. input. Sentinel $\mathbb{E}$ Enterprise. May 2, 2007.

20. Gostin LO, Hodge JG. Personal privacy and common goods: a framework for balancing under the national health information privacy rule. Minn L Rev. 2002;86: 1439-1480.

21. 5 CFR 160.203 (a) (iv).

22. Pinkerton JP. We can't afford to be a nation of soft angels. Newsday. April 19, 2007:A37.

23. Mental health is criterion that should affect gun buys. Portland Press Herald. April 20, 2007:A6.

24. Smith RB, Fleming DL. Student suicide and colleges' liability. The Chronicle Review. April 20, 2007. http://chronicle.com/free/v53/i33/ 33b02401.htm. Accessed May 24, 2007.

25. 20 USCA $\$ 1232 \mathrm{~g}$

26. 34 CFR § 99.31(a)(10). 